\title{
Challenges for the dental radiology clinic in times of the COVID-19 pandemic
}

\author{
Paulo Victor Teixeira Doriguêtto ${ }^{1} \cdot$ Julia Pereira Americano ${ }^{1} \cdot$ Karina Lopes Devito ${ }^{2}$ (i)
}

Received: 28 May 2020 / Accepted: 12 June 2020 / Published online: 20 June 2020

๑ Japanese Society for Oral and Maxillofacial Radiology and Springer Nature Singapore Pte Ltd. 2020

\begin{abstract}
This letter addresses the challenges for the dental radiology clinic in times of the COVID-19 pandemic. It highlights the use of teleradiography and mobile devices, as well as the proper care in disinfecting these equipments. As there are still no specific therapies for COVID-19, biosafety measures that promote containment and prevent the spread of the virus are crucial to stop the outbreak and control a possible new infectious peak.
\end{abstract}

Keywords COVID-19 $\cdot$ Coronavirus $\cdot$ Dental radiology

The new coronavirus has caused negative impacts and paralyzed professional activities considered to be at high risk of contamination worldwide. Due to the large release of aerosols from dental procedures, dentistry, in the vast majority of countries, has been restricted to urgent and emergency care, such as odontogenic infections or trauma [1].

For a complementary diagnostic, in these cases, imaging exams are often necessary. Thus, the use of extraoral images, such as panoramic radiography or cone beam computed tomography, has been recommended. When intraoral imaging is required, sensors must be two-layer barriered to prevent perforation and cross-contamination [2].

It has also been proposed that dental radiology clinics should preferably use teleradiology or work flow with digital radiography. Work flow with digital radiography is understood as the process of the acquisition of radiographic images, written radiology reports and sending the respective images through online platforms, enabling the clinician to receive the digital image on his cell phone, computer or similar. The justification is that due to this modality, there is less risk of dissemination and contamination by harmful agents,

Karina Lopes Devito

karina.devito@uff.edu.br

1 Master's Program in Dentistry, School of Dentistry, Federal University of Juiz de Fora, Juiz de Fora, MG, Brazil

2 Department of Dental Clinic, School of Dentistry, Federal University of Juiz de Fora, Campus Universitário, s/n, Juiz de Fora, MG 36036-900, Brazil considering that in the traditional work flow the exam passes through several hands until it reaches the clinician [3].

In fact, digital images benefit communication and the exchange of information between professionals. Mobile devices (MD) are increasingly having their routine use extrapolated and being used as an important tool aid in the areas of education and health, including dentistry [4-6]. It is also known that the evaluation of the radiographic image from these devices, such as desktop, laptop, tablet or smartphone that, although have different screen sizes and resolution, do not compromise the diagnostic accuracy $[7,8]$.

However, it is necessary precaution when using MD in the clinical setting. The potential of MD to act as reservoirs of pathogens capable of causing cross-infections is already well established in the literature. This potential has greatly increased after the greater availability of touchscreen technology $[9,10]$. Recent studies have show that the new coronavirus remains viable for up to 3 days on stainless steel and plastic surfaces [11], 4 days on glass and 5 days on metal [12], all materials used to make MD. It is encouraged, therefore, that professionals should proceed to chemical disinfection of the surfaces of these equipments with $70 \%$ isopropyl alcohol, which does not compromise the electronic components of the devices, in addition to applying routine preventive protocols, such as hands hygiene, disinfection of the environment and the use of personal protective equipment $[2,13]$.

In addition, as images are usually sent through online platforms, viewed and stored on digital media, professional users of MD should be aware of the vulnerabilities and 
dangers of their use, especially regarding the possible sharing of patient information. It is important to take the correct actions to protect confidential data $[14,15]$.

As there are still no specific therapies for COVID-19, biosafety measures that promote containment and prevent the spread of the virus are crucial to stop the outbreak and control a possible new infectious peak.

\section{Compliance with ethical standards}

Conflict of interest Paulo Victor Teixeira Doriguêtto declares that he has no conflict of interest. Julia Pereira Americano declares that she has no conflict of interest. Karina Lopes Devito declares that she has no conflict of interest.

Human and animal rights This article does not contain any studies with human or animal subjects performed by the any of the authors.

\section{References}

1. Meng L, Hua F, Bian Z. Coronavirus disease 2019 (COVID-19): emerging and future challenges for dental and oral medicine. J Dent Res. 2020;99(5):481-7. https://doi.org/10.1177/0022034520 914246.

2. Ather A, Patel B, Ruparel NB, Diogenes A, Hargreaves KM. Coronavirus disease 19 (COVID-19): implications for clinical dental care. J Endod. 2020;46(5):584-95. https://doi.org/10.1016/j. joen.2020.03.008.

3. Saki M, Haseli S, Iranpour P. Oral radiology center as a potential source of COVID-19 transmission; points to consider. Acad Radiol. 2020. https://doi.org/10.1016/j.acra.2020.04.040.

4. Estai M, Kanagasingam Y, Huang B, et al. Comparison of a smartphone-based photographic method with face-to-face caries assessment: a mobile teledentistry model. Telemed J E Health. 2017;23(5):435-40. https://doi.org/10.1089/tmj.2016.0122.

5. Sarode SC, Sarode GS, Anand R, Patil S, Unadkat H. WhatsApp is an effective tool for obtaining second opinion in oral pathology practice. J Oral Pathol Med. 2017;46(7):513-9. https://doi. org/10.1111/jop.12515.

6. Pontual MLA, do Nascimento EHL, da Cruz Perez DE, Pontual AA, Ramos-Perez FM. Challenges in oral radiology teaching during COVID-19 pandemic. Dentomaxillofac Radiol. 2020;49:20200178. https://doi.org/10.1259/dmfr.20200178.

7. Giacomini GO, Antonioli C, Tibúrcio-Machado CS, Fontana MP, Liedke GS. The use of smartphones in radiographic diagnosis: accuracy on the detection of marginal gaps. Clin Oral Investig. 2019;23(4):1993-6. https://doi.org/10.1007/s00784-019-02848-6.

8. Vasconcelos TV, Santaella GM, Nascimento HA, Rovaris K, Ambrosano GM, Freitas DQ. Digital radiographs displayed on different devices: effect on the detection of vertical root fractures. Int Endod J. 2016;49(4):386-92. https://doi.org/10.1111/iej.12466

9. Bhardwaj N, Khatri M, Bhardwaj SK, Sonne C, Deep A, Kim KH. A review on mobile phones as bacterial reservoirs in healthcare environments and potential device decontamination approaches. Environ Res. 2020;186:109569. https://doi.org/10.1016/j.envre s.2020.109569.

10. Kotris I, Drenjančević D, Talapko J, Bukovski S. Identification of microorganisms on mobile phones of intensive care unit health care workers and medical students in the tertiary hospital. Med Glas (Zenica). 2017;14(1):85-90. https://doi.org/10.17392 1878-16.

11. van Doremalen N, Bushmaker T, Morris DH, et al. Aerosol and surface stability of SARS-CoV-2 as compared with SARS-CoV-1. N Engl J Med. 2020;382(16):1564-7. https://doi.org/10.1056/ NEJMc2004973.

12. Kampf G, Todt D, Pfaender S, Steinmann E. Persistence of coronaviruses on inanimate surfaces and their inactivation with biocidal agents. J Hosp Infect. 2020;104(3):246-51. https://doi. org/10.1016/j.jhin.2020.01.022.

13. Brady RR, Chitnis S, Stewart RW, Graham C, Yalamarthi S, Morris K. NHS connecting for health: healthcare professionals, mobile technology, and infection control. Telemed J E Health. 2012;18(4):289-91. https://doi.org/10.1089/tmj.2011.0147.

14. European Society of Radiology (ESR). ESR paper on the proper use of mobile devices in radiology. Insights Imaging. 2018;9(2):247-51. https://doi.org/10.1007/s13244-017-0589-7.

15. European Society of Radiology (ESR); European Federation of Radiographer Societies (EFRS). Patient Safety in Medical Imaging: a joint paper of the European Society of Radiology (ESR) and the European Federation of Radiographer Societies (EFRS). Insights Imaging. 2019;10(1):45. https://doi.org/10.1186/s1324 4-019-0721-y.

Publisher's Note Springer Nature remains neutral with regard to jurisdictional claims in published maps and institutional affiliations. 